\title{
Continuous chemical production processes
}

\author{
John A. Glaser
}

Published online: 28 January 2015

(C) Springer-Verlag Berlin Heidelberg (Outside the USA) 2015

The American Chemical Society Green Chemistry Institute Pharmaceutical Roundtable recently reported its efforts to determine the value of continuous processing, in contrast to step-wise protocols, as a key area for green engineering. A group of 8 pharmaceutical firms participated in this study. The initial hurdle was to assemble information and agree on a procedure to assess the "business case for continuous manufacturing." The "business case" concept is expected to provide an estimate of the profitability of an investment opportunity through scenario analysis.

Examples of continuous manufacturing were assembled from multiple member companies and ranged across the

J. A. Glaser $(\bowtie)$

National Risk Management Research Laboratory, US

Environmental Protection Agency, 26 W King Dr, Cincinnati, OH 45268, USA

e-mail: Glaser.John@epa.gov features of materials/waste savings, smaller footprint/ smaller plants, company goals (e.g., $\mathrm{CO}_{2}$ emission control), investment for new processes/plants, and green reputation. A format for information was established for scoping the business case. Major benefits of this analysis were shown to be concentrated in investment saving, yield/quality improvement, safety, and speed of operation. Benefits to business analysis were recognized not as an end but a beginning of process development by the participants. Equipment and infrastructure issues important to continuous manufacturing could be risk-eliciting issues.

An example of these directions to use continuous manufacturing can be found in the recently reported multistep synthesis and workup sequence for the small molecule, aliskiren hemifumarate (a direct renin inhibitor used as an antihypertensive drug). Starting with advanced intermediates, the synthesis plant completed the conversion through two synthetic steps to the final active pharmaceutical ingredient. The 1st step involved solvent-free, molten conditions at high temperature leading to $90 \%$ yield. Solid handling and long residence times were avoided. The product stream was treated with inline liquid-liquid extraction with membrane-based separators scaled for microfluidic implementation providing continuous crystallization, filtration, and washing. The 2 nd step used aqueous acid conditions to deprotect the substrate. Base neutralization completed the conversion chemistry in yields of $90-95 \%$. Multiple runs were conducted corresponding to a nominal throughput of $41 \mathrm{~g} / \mathrm{h}$ over $240 \mathrm{~h}$ of operation. The authors emphasize that the plant demonstration revealed the necessity of undertaking a reevaluation of the entire pharmaceutical process when undertaking conversion to a continuous flow system since the steps for the flow process may be different than an established batch process. 
<smiles>COCCCOc1cc(C[C@@H](C[C@H](N)[C@H](O)C[C@H](C(=O)NCC(C)(C)C(N)=O)C(C)C)C(C)C)ccc1OC</smiles>

Aliskiren hemifumarate synthesis

Org Process Res Dev 2013, 17, 1472-1478; 2014, 18, 402-409; 15, 900-911.

\section{Crop yield changes under climate change and adaptation}

Demands of the global population continue to stress food production. The prospects for food security have been recognized to be a function of yield and a range of agricultural and climatic consequences. A wide range of related studies can be subjected to meta-analysis to pool and compare results pertinent to a question where such studies can lead to a summary of the range of projected outcomes and assessment of the consensus. In this role, meta-analysis enables the identification of projection differences and their causes. The absence of model documentation and model experiment standardization complicates the analysis.

This report offers the results of using a meta-analysis to determine the effect of climate change on crop yield, during this century, through the use of local mean temperature during the growth period as a change metric. The new dataset employed in this analysis contained of more than 1,700 published simulations to evaluate yield impacts of climate change and adaptation. Temperature increases of $2{ }^{\circ} \mathrm{C}$ were assessed as benefiting wheat, rice, and corn (maize) yields. However, increased warming beyond $2{ }^{\circ} \mathrm{C}$ was found to be detrimental to the selected crops. Simulated crop-level adaptations had a significantly positive effect on all crops, regions, and levels of warming. Adaptation to wheat yields plateaus at about $16 \%$. Anticipated losses in aggregate production of wheat, rice, and maize in both temperate and tropical regions by $2{ }^{\circ} \mathrm{C}$ of local warming are foreseen in the meta-analysis. Crop-level adaptations increase simulated yields of wheat and rice of 7-15\%, on average, attributable to crop-level adaptation was not found with corn (maize). With increasing temperatures yield, losses for the second half of the century are greater than the first 50 years. Climate change impacts and adaptive potential as a function of temperature were simulated in this study with and evaluation of predictive uncertainty, the timing of impacts, or quantitative effectiveness of adaptation. The use of meta-analysis can offer insight into questions where information has not been directly assembled and connected but relevant unassociated studies exist. The importance of model documentation and experimental standardization to meta-analysis is pivotal to successful utilization of this technique. A complementary study was conducted on rice showing the importance of greenhouse gas emissions from rice paddies and the effect of increased atmospheric $\mathrm{CO}_{2}$ with rising temperature on rice yield.

Nature Climate Change 2014, 4, 287-291; 2013, 3, 288-291. 


\section{Energy and GHG reductions with catalytic processes}

Globally, chemistry is involved in manufacture processes exceeding $95 \%$ of all products. The chemical industry contributes to products in three wide ranges of materials: base chemicals, specialty chemicals, and consumer chemicals. These product ranges provide growth to the global economy and development in emerging countries. Ironically, the chemical industry uses large quantities of energy; but manufactures products and employs technologies are used in a wide array of energy saving and/or renewable energy applications. For instance, the largest industrial energy user is the chemical and petrochemical sector which accounts for $10 \%$ of total worldwide energy demand and $7 \%$ of global greenhouse gas (GHG) emissions.

The chemical industry employs $42 \mathrm{EJ} / \mathrm{year}$ (including feedstock) translating into $10 \%$ of the global energy demand or $30 \%$ of the total worldwide industrial energy demand. Global chemical production generates $5.5 \%$ of $\mathrm{CO}_{2}$ emissions or $7 \%$ of global GHG emissions. Chemical

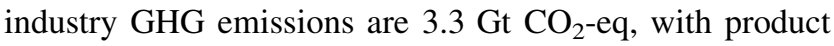

approach 13 EJ by 2050 which is equivalent to the current annual primary energy requirements of Germany.

Due to the global economic, environmental, and social pressures on global society, there is a significant lack of focus on sustainability found in current energy supply and use. $\mathrm{CO}_{2}$ emissions related to energy use are expected to double by 2050 . The security of fossil energy supplies can intensify apprehensions important to increased demand.

Catalysts are known to increase the rate of reaction generally without being consumed in the reaction contributing to production efficiency enhancement with potential energy use reduction. Eighteen chemical manufacturing processes account for $80 \%$ of energy demand and $75 \%$ of GHG emissions of the chemical industry. The 18 industrial processes synthesize acrylonitrile, caprolactam, cumene, ethylene glycol, phenol, polyethylene, propylene oxide, polypropylene, $\mathrm{p}$-xylene, styrene, terephthalic acid, vinyl chloride, methanol, propylene, ethylene, and ammonia. An example of the ammonia process using steam reforming is as follows:
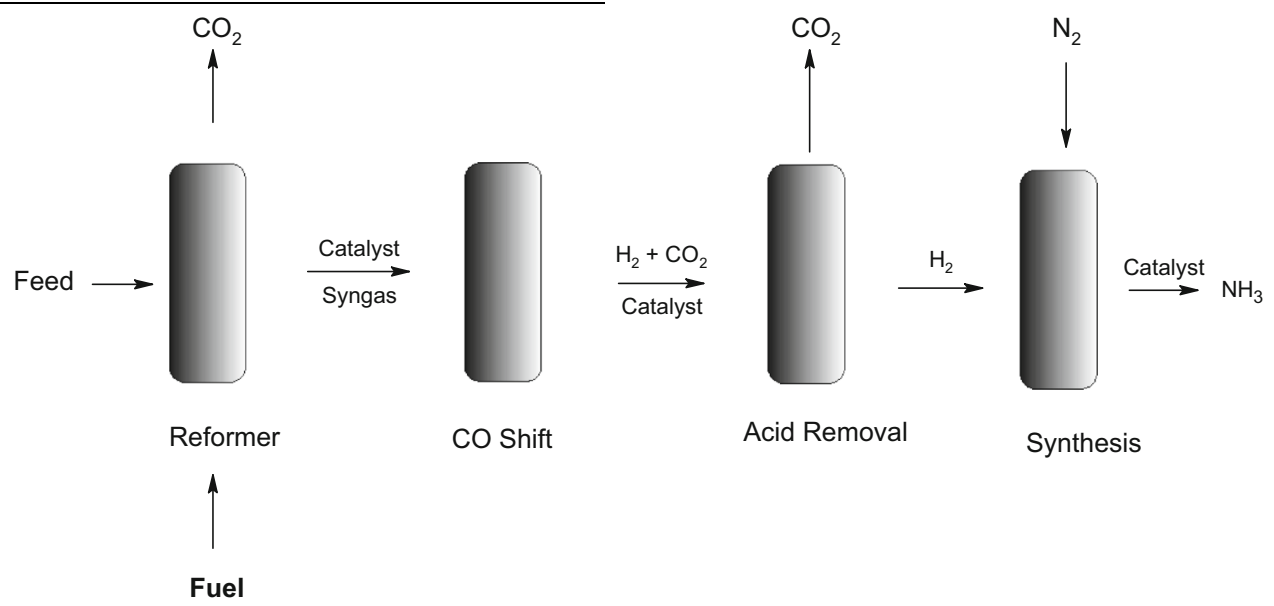

Ammonia Synthesis

manufacture contributing $2.1 \mathrm{Gt}$ and extraction of feedstock/fuel and disposal phases contributing 1.2 Gt. Product manufacture offers targets for finer control of energy consumption and related GHG emissions.

The International Energy Agency, in partnership with DECHMA and the International Council of Chemical Associations, has released a roadmap focused on the role of catalytic processes in reducing energy use and GHG emissions in the chemical sector. Some $90 \%$ of chemical processes use catalysts for efficient production. Catalysis is an important technology having efficiency improvement potential. Energy savings potential was calculated to
Catalysts and process improvements are perceived lead to reduced energy intensity for these products by 20-40\% as a whole by 2050 combining all considered scenarios. Identification of the necessary steps accelerating the implementation technology changes, this roadmap enables partners (government, industry, and financial firms) to make well-designed choices. Sustainability concerns, rising energy costs, and competitive pressures have motivated the development of this roadmap for the chemical and petrochemical industry investigating how catalytic processes can contribute to further increasing efficient use of energy and reducing emissions of GHGs. 
http://www.iea.org/publications/freepublications/publica tion/Chemical_Roadmap_2013_Final_WEB.pdf

\section{Landfill mining}

Stocks of metals and other related materials have been shown to be increasingly scarce due to dwindling natural sources. Mining recovery of these materials has been very challenging, since waste streams and environmental pollution associated with metal extraction can be extensive. Landfill mining involves excavation, processing, treatment, and/or recovery of landfilled materials. In specific cases, landfill mining has been found to be economically justified solely despite a host of down-side considerations. This study was designed to analyze the quantity of material contained in Swedish municipal solid waste landfills. The analysis focused on quantity of extractable and recyclable materials and a delineation of the resource and climate implications of resource recovery associated with landfill mining.

Two scenarios were used in the analysis to explore the importance of different conventional separation technologies. A mobile separation plant was contrasted to a more advanced stationary separation plant. Using a Monte Carlo simulation, each of the processes was evaluated in specific scenarios to address the uncertainty. More than 350 million Mt waste materials were found in several thousand municipal landfills. Combined with resource recovery, landfill mining with a contemporary stationary separation plant could recover some 7 million $\mathrm{Mt}$ of ferrous metals and 2 million Mt of nonferrous metals. The study estimates that landfill mining could contribute to the equivalent of a onetime reduction some 50 million $\mathrm{Mt}$ of $\mathrm{CO}_{2}$ equivalents.

J Indust Ecol 2013, 17, 742-755.

\section{Metal recycling issues}

Sustainable development calls for the establishment of a system supporting enterprise development that is carefully focused on equal footing of environmental, social, and economic features. The challenge of sustainable development at the beginning of the 21 st century has become a systemic one, with environmental, social, and economic dimensions on an equal footing. UNEP and a UNEP-hosted International Resource Panel have produced a recent 320 page report: Metal Recycling-Opportunities, Limits, Infrastructure to provide scientific information designed to assist policy makers in the practice of optimal metal recycling in terms of economics and technology related to product life cycles implicit to sustainable metals management. The report promotes resource efficiency, improved materials recycling, and life-cycle thinking as a systemic approach.
The recommendations related to management require more than the simple improvement of selected material recycling rates. The report advocates a change of mindset by moving to a product-centric approach rather than the traditional material-centric approach. Complexity of products and complex interactions of component within recycling systems part have made recycling more difficult in today's society with an attendant loss of value. Common commodity metals are recovered easily as in the case of steel, magnesium, and copper. Easy removal of these metals from unwanted components assists recovery. Complex devices such as cell phones may contain in excess of 40 elements ranging from commodity to precious/platinum group metals. For instance, it is estimated that a modern automobile contains all commercially available metals. An automobile is constructed of a broad range of metal-containing products integrated into the vehicle. Optimizing the recycling of entire products at their end-oflife instead of focusing just on the recyclable materials contained in the product becomes exceptionally important. Efficient recycling systems, resource efficiency, sustainable development supporting a green economy, and poverty eradication are anticipated results of a product-centric view of recycling. As core raw materials for infrastructure and manufacturing of products, metals are essential to the global economy.

Strong demand is expected to continue into the future especially in the developing world with rapid industrialization and the requirements of modern techniques employed in the developed world. This report provides insight into the potential environmental impacts of metals at different stages across the life-cycle and offering connections to other areas of resource use such as water, food production, and energy. The report finds recycling to be a positive component of an integrated approach to achieve sustainability. Metal production from ore devours about a two order magnitude more energy per kg produced metal in contrast to recycled metals.

http://www.unep.org/resourcepanel/Portals/24102/PDFs/ Metal_Recycling_Full_Report.pdf

\section{Chemical reaction space}

Each chemical reaction can be characterized as a unique solution to a chemical conversion. The distinctiveness of reaction conditions for a given reaction is not necessarily optimal or unique. Many year of process optimization have shown this to be true. As one has conducted process improvement research, an established theme or direction is explicit to the experimental research. Generally, this collimated vision asserts reaction conditions to be narrowly confined in a rather discrete portion of reaction space. In 
this article, the authors consider the optimization of a typical transition metal-catalyzed reaction (Suzuki-Miyaura reaction) to form biaryls.<smiles>[R]c1ccc(B(O)O)cc1</smiles><smiles>[R]c1ccc(C)cc1</smiles>

metabolic breakdown of organic matter in the absence of oxygen. Many different forms of organic matter can be utilized in the form of waste material from plants, animals,

$$
\mathrm{R}=\text { halide or pseudohalide }
$$

Parameters that may affect a reaction can be easily distinguished as either continuous or discrete. Continuous parameters can be addition rate concentration, $\mathrm{pH}$, and stoichiometry as examples. Discrete parameters can include agitation method, reaction vessel geometry, and order of addition. This delineation holds for both catalytic and noncatalytic reactions. An informed estimate of the millions of parameter settings required to optimize one typical transition metal-catalyzed reaction can be assembled through the use of design of experiments and principal component analysis techniques to reduce the number potential reaction settings to a practical few and the number of required experiments necessary to avoid losing critical information. The authors point to the ability to relate discrete or discontinuous parameters to one another as a key element. Any reaction can be assessed by this methodology. An estimate of potential permutations possible for these types of reactions in particular can significantly assist reaction optimization. The quantification of experiments required to assess the complexity and sheer size of catalysis in a "reaction space," for homogeneous catalysis can be greatly useful to the experimenter or process designer.

Org Process Res Dev 2013, 17, 40-46; Chemica OggiChemistry Today 2012, 30, 74-76.

\section{Biogas $\mathrm{CO}_{2}$ adsorption on metal-organic frameworks}

Biogas as a renewable energy source is composed of methane $\left(\mathrm{CH}_{4}\right)$, carbon dioxide $\left(\mathrm{CO}_{2}\right)$, and small amounts of hydrogen sulfide $\left(\mathrm{H}_{2} \mathrm{~S}\right)$ with other minor volatiles. For use as an alternative fuels, biogas must be upgraded to produce purified $\mathrm{CH}_{4}$. Biogas is formed through the and humans. The components of biogas reduce the caloric value of biogas. With $30-40 \% \mathrm{CO}_{2}$ content, most biogas sources require upgrading through the removal of $\mathrm{CO}_{2}$. Current removal technologies can consume 3-6\% of the energy contained in the biomass with significant cost features.

Metal-organic frameworks (MOFs) are molecular assemblages of porous coordination polymers using a metal (connector) and a ligand (link) via self-assembly to form porous crystalline structures, where metal-ligand bonds bind the connectors and ligands together. The construction of MOFs from metal coordination bonds between metal atoms and multidentate ligands or metal-containing clusters (secondary building units) provides central structural cavities that are much larger than other traditional adsorbents required for gas storage. These novel adsorbents are characterized by their high crystallinity, high surface areas, high gas storage, high regenerability, large pore volumes essential to gas separation and storage, and robustness. The chemistry of such coordination polymers can be easily tuned to specific compositions thus permitting the possibility of very difficult separations form gas phase. High selectivity toward $\mathrm{CO}_{2}, \mathrm{H}_{2} \mathrm{~S}$, and $\mathrm{SO}_{2}$ has been found with a novel-fluorinated MOF synthesized using commercially available 2,2-bis (4-carboxyphenyl)hexafluoropropane to form a zinc MOF.

Chem Soc Rev 2013, 42, 9304-9332.

\section{Reforestation as ozone control}

The pervasive and damaging air pollutant, ozone $\left(\mathrm{O}_{3}\right)$ has been found in background concentrations which have shown increase of more than $100 \%$ in the northern 
hemisphere since the nineteenth century. Recent research suggests that reforestation can be used to reduce the cost of compliance to ambient air quality standards for ozone with possible ancillary benefits unavailable with established pollution control technology. In this research, a hypothetical 405-ha area near Houston, Texas was used to evaluate this new control strategy as cost effective in contrast with traditional pollution control technology.

A modified urban forest effects model simulated tree growth and canopy development at the hypothetical Houston-area site by quantifying total pollutant removal attributable to reforestation using ambient data of local modeling and meteorological information including temperature, solar intensity, and dew point. This simulation of reforestation was shown to remove the equivalent of up to 209 tons of regulated nitrogen dioxide emissions. Nitrogen dioxide removal was found to favorably compare with conventional technology installation costs. As a costeffective control technology, large-scale reforestation connected with urban areas could reduce ambient ozone concentrations on nonattainment areas as modeled through this research. Analysis of the hypothetical project indicated that reforestation as a control technology could provide control of ground-level ozone concentrations to be a viable approach complementing conventional controls. The authors suggest that potential sites in the US., where reforestation could be used to abate ozone include areas in New York, New Jersey, Pennsylvania, Michigan, and California. Where public land in not owned in non-attainment areas, the land costs could make the use of reforestation unattainable.

PNAS 2014111 (40) E4204-E4213.

\section{Green purification techniques for acid mine drainage}

Mining processes for extraction of metal-bearing terrestrial strata lead to the generation of acid mine drainage (AMD) and cyanide processing extraction effluents having negative impacts for receiving waterways and ecological biodiversity. These effluents contain valuable constituents worthy of separation and offer incentives derived from enhanced resource recovery processes that are more efficient than current technology and tailored to environmental constraints.

Recovery of heavy metals and other prized assets in these effluents can be pursued through separation technology. Adsorption, membrane separation, and chemical modification offer specific routes leading to the selective recovery of valuable materials. Chemical techniques useful to this enterprise include ion-exchange, acidification, volatilization, neutralization, sulfide formation, thickening, and membrane technology are processes useful to recovery from these waste streams. With the guidance of green engineering principles improved performance of the recovery technologies, the authors assert that this can be accomplished.

Energy use, chemical consumption, and the formation of waste for purification and recovery techniques are the main environmental disadvantages. Limitations are expected to be surmounted through process efficiency improvements and employing renewable energy. Hybrid purification and recovery processes may offer significant advantages.

AMD is a natural process occurring as sulfide mineral oxidation through exposure to the atmosphere. Exposure of walls in open pits, underground structures, crushed waste rock, and tailings to water and oxidizing atmosphere contributes to the release of the contaminating chemicals.

AMD causes considerable damage to the environment which is incurred while the mine is actively operated and into the post operation period where management is minimal. The effluents are characterized by low $\mathrm{pH}$, high osmotic potential, the presence of toxic metals and metalloids, and particulate materials formation and deposition are critically important to the fauna and flora of the region. The recovery of valuable compounds from AMD and cyanide processing effluents will generally build the environmental sustainability of the mining industry. Effluent treatment attracts much of the current research focus. Recovery of valuable constituents is slowly developing, and demands for the constituents can provide the necessary economic impetus to aid the development of this needed technology.

J Chem Technol Biotechnol 2014, 89, 803-813.

\section{Climate change contribution to US economic risks}

The US is not exempt from the economic risks associated with climate change. The size and geographic diversity of the US show that these risks vary across the regions. The privately supported Risky Business Project has recently released a 52 page report: Risky Business-The Economics of Climate Change in the United States.

This report reveals research designed to elucidate risks associated with climate change across the US. Climate impacts were found to be extremely diverse for all US regions. The analysis showed that each region and sector of the economy must understand that the planet is quietly warming and there will be significant consequences.

US partisan debate in the climate conversation has not led to solutions so that the realty of the science or whether solutions are either job destroyers or creators remains debatable. Modeling of temperature increases and rising sea effects associated with warmer climate can be difficult. Conversion of these physical impacts to economic 
consequences is a greater challenge. The authors suggest that all government and business decision making must be designed to incorporate the latest information in assessments. All business and government efforts must be highly cognizant to react properly to catastrophic events derived from climate risk. Different features of weather and planning will be important to areas such as homes at risk from storm surge where climate risk analysis must be made part of the business decisions.

The report hastens to add that precious little time is available for the necessary preparations. Regional effects will be encountered with different effects. Emergency services could be easily overwhelmed. Dislocation of services and health care could be compromised as we observed in New Orleans during Hurricane Katrina. The authors insist that a call to action is the only response available in this late hour. The cooperation of governments and business is pivotal to meeting the climate change challenge.

http://riskybusiness.org/

\section{Coal use costs}

The Carbon Tracker initiative has released a 28 page report: Carbon Supply Cost Curves-Evaluating Financial Risk to Oil Capital Expenditures which tackles the questions of investment and risk within the petroleum production sector. Using a $2{ }^{\circ} \mathrm{C}$ carbon budget context that is predicated on a significant reduction in future oil demand, the global supply and demand for petroleum through 2050 were examined. The private-sector petroleum companies are expected to invest in excess of $\$ 1$ trillion in upstream capital expenditures. High cost oil projects in excess of $\$ 80 / \mathrm{bbl}$ require market prices in excess of $\$ 95 / \mathrm{bbl}$. There are high cost projects planned for the 2014-2050 timeframe that is expected to make up 29 million barrels per day of the total global potential oil production for this time period. Carbon asset control is expected to be an important priority to capital stewards. Investors are cautioned to inspect company investment plans more thoroughly to identify the trends of falling returns and increased capital intensity (capital expenditures/barrel). The Carbon Supply Cost Curve has been introduced to enable stress testing of the logic for upstream capital expenditure. These curves identify potential petroleum supply as cumulative oil production (barrels per day) and $\mathrm{CO}_{2}$ emissions (tons of carbon dioxide). The breakeven oil price ("price at which an asset yields a net value of zero, with a $10 \%$ internal rate of return") is used to analyze the economics of oil projects. This analysis enables investors to evaluate capital allocations relative to the risk. Exposure scenarios for private companies are explored too. The Carbon Tracker initiative is a project of nonprofit company, Investor Watch, which was founded to align capital markets with social and ecological sustainability.

http://www.carbontracker.org/report/carbon-supplycost-curves-evaluating-financial-risk-to-oil-capitalexpenditures/

\section{Climate science questions answered!}

A 36 page report Climate Change: Evidence and Causes, was released by the US National Academy of Sciences and the Royal Society, the national science academies of the US and the UK. A question and answer form is used to offer evidence supporting climate change caused or synergistically abetted by recent humankind. The report points out that public debate continues and the denial side of the argument is aided by the apparent recent slowdown of global warming. The question and answer format provides information and evidence for the implication of the human contribution to climate change, changes in the rate of global warming, and other areas of interesting debate. The report asserts that there is scientific consensus concerning the effects of human contributions to climate change. The human contributions to climate change are recognized as a matter of scientific consensus.

The report stresses that atmospheric carbon dioxide has increased to concentrations not recorded in the last 800,000 years. Combustion of fossil fuels is identified as a major cause of this change. Correlation of climate change and extreme weather events and accurately predicting the extent of future sea-level rise are areas of continuing uncertainty. The variability of effects assembled to support the assertion that climate changes do not invalidate our understanding of long-term changes to the climate. The periodicity of warm and cold times will continue but will be rarer with the passage of time.

http://dels.nas.edu/resources/static-assets/exec-officeother/climate-change-full.pdf

\section{Dow Jones sustainability indices review 2014}

The first global index tracking the business performance of leading worldwide sustainability-driven companies is the Dow Jones Sustainability Index (DJSI) which is derived from an analysis of economic, environmental, and social factors. In this, the 15 th anniversary of the DJSI, more than 3,000 companies were invited in the S\&P Dow Jones Indices' and RobecoSAM's Corporate Sustainability Assessment from which the DJSI is derived. The integrated assessment of the economic, environmental, and social criteria using a rule-based methodology offers long-term 
insight into shareholder value. A total of 1,813 companies were analyzed leading to a best-in-class determination for companies ranging across all industries in their ability to outperform others as indicated in the sustainability metrics scores. Criteria of tax strategy, social \& environmental reporting, human capital development, and performance scoring constitute the assessment criteria changes for 2014. A series of eight indices are developed as follows: DJSI World, DJSI Asia Pacific, DJSI Emerging Markets, DJSI Europe, DJSI North America, DJSI Australia, DJSI Korea, and DJSI World Enlarged. In the case of the DJSI World index, 2,500 largest companies of the S\&P Global Broad market Index, 59 RobecoSAM industries across 47 countries were used as the database to conduct the evaluation. Application of the sustainability metrics yielded 319 components, 59 RobecoSAM Industries, in 26 countries. The evaluation can lead to the addition or subtraction of firms to the index. For the 2014 exercise, 32 were added and 46 were deleted. The indices offer comparison to show market returns similar to a broad-based index of securities. The indices are not actively managed hand do not have costs, fees, or other expenses associated with their performance. It is not possible to invest directly in an index.

http://www.sustainability-indices.com/review/annualreview-2014.jsp

\section{Streams restoration in mountaintop reclamation}

Compensatory mitigation is commonly used to replace aquatic natural resources being lost or degraded but little is known about the success of stream mitigation. This article presents a synthesis of information about 434 stream mitigation projects from 117 permits for surface mining in Appalachia. Data from annual monitoring reports indicate that the ratio of lengths of stream impacted to lengths of stream mitigation projects was $<1$ for many projects, and most mitigation was implemented on perennial streams, while most impacts were to ephemeral and intermittent streams. Regulatory requirements for assessing project outcomes were minimal; visual assessments were the most common; and $97 \%$ of the projects reported suboptimal or marginal habitat even after 5 years of monitoring. Less than a third of the projects provided biotic or chemical data; most of these were impaired with biotic indices below state standards and stream conductivity exceeding federal water quality criteria. Levels of selenium known to impair aquatic life were reported in 7 of the 11 projects that provided selenium data. Overall, the data show that the mitigation efforts being implemented in southern Appalachia for coal mining are not meeting the objectives of the Clean Water Act to replace lost or degraded streams ecosystems and their functions.

Environ Sci Technol 2014, 48, 10552-10560.

\section{New journal}

Environmental technology and innovation

This new journal focuses on solutions to environmental technology development formed from a marriage of natural sciences and technology engineering directed to understand and provide a sustainable future. The creation and development of new innovative products, technologies, and ideas are necessary for the improvement of the environment. All environmental media are targeted for scrutiny in rural and urban settings. This platform is designed to aid the distribution and use of fundamental scientific information supporting environmental protection and sustainable development. Smarter and cleaner technologies can be developed through the proper use of science and technology with innovative applications. Resource and energy use are important to the development of these technologies and their future dissemination.

http://www.journals.elsevier.com/environmental-tech nology-and-innovation/ 